past year of white fungus on the muzzles and wings of a small number of bats in at least eight European countries. Four countries - Hungary, Germany, Switzerland and France ${ }^{1}-$ have confirmed that the fungus is Geomyces destructans, but their bats remain healthy.

Adding to the intrigue is a 1983 report that shows a picture of a German bat with powdery white substance around its muzzle ${ }^{2}$. The report mentions occasional sightings of such bats during routine winter bat surveys, suggesting that the fungus may have been infecting European bats for at least 23 years, apparently without killing them, before showing up in North America.

According to David Blehert, a microbiologist at the US Geological Survey's National Wildlife Health Center in Madison, Wisconsin, whose team first described the fungus ${ }^{3}$, the European bats may have coevolved with the fungus and developed immune resistance. They may also have behavioural adaptations that allow them to escape lethal infection; for example, European bats hibernate in small groups, ranging from 1 to rarely more than 100 , whereas bats in the United States usually hibernate in groups of thousands or hundreds of thousands, ripe for rapid spread of disease.

"It will be interesting to see what the situation is in two to three years from now," says Blehert. "If the fungus they're seeing now is the same fungus that was anecdotally documented three decades ago, it does suggest that while Geomyces destructans occurs in Europe, white-nose syndrome may not."

But time is not on the side of North American bats. "Any day now I'm expecting the phone to ring with reports of new locations," says Coleman, who is particularly anxious about the disease spreading south and west (see graphic). "Tennessee, Kentucky - those are places with huge numbers of bats," he says.

Little brown bats, the predominant species in the Mount Aeolus cave, have been hardest hit, says Thomas Kunz, a biologist at Boston University in Massachusetts. And with the bats normally only producing one pup per year, the populations will struggle to come back.

"We're making predictions of extinction," he says.

\section{Lizzie Buchen}

1. Puechmaille, S. J. et al. Emerg. Infect. Dis. advance online publication doi:10.3201/eid1602.091391 (2010).

2. Feldmann, R. in Die Säugetiere Westfalens (eds

Schröpfer, R., Feldmann, R. \& Vierhaus, H.) 107-111

(Westfälisches Museum für Naturkunde, 1984).

3. Blehert, D. S. et al. Science 323, 227 (2009)

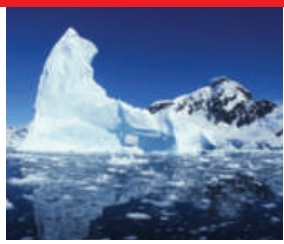

OCEANS RELEASE DDT

Emissions of controversial pesticide are heading northwards.

go.nature.com/ZVw7VN

\title{
Trace that metal
}

Ocean life, like human life, needs trace metals to stay healthy, and in some cases even to survive. But although the cycles and concentrations of the ocean's superstar nutrients - phosphorus and nitrates - are relatively well understood, a clear global view of trace metals has remained elusive.

Next month, however, an international team will formally launch a major research programme to obtain measurements of trace metals throughout the world's oceans. Potential pay-offs range from improved understanding of the role of ocean plankton in regulating climate change, to better studies of the geological history of the oceans.

"We're completely missing information about iron and other metals which are really important to life, and that renders our current understanding of the nutrient system incomplete," says the project's steering committee co-chair Gideon

Henderson, a geochemist at the University of Oxford, UK.

The programme, called GEOTRACES, involves more than 30 countries and will span the next decade. More than a dozen cruises are planned - the first returned to port on 9 January after sampling in the Indian Ocean - and at least ten more are being discussed. All told, the programme will cost US\$100 million to $\$ 200$ million.

GEOTRACES' primary mission is to analyse water samples from various depths, recording levels of trace elements such as iron and cobalt that are hard to measure because the sampling apparatus must be carefully cleaned to avoid contamination. The data should allow investigators to model the sources and cycles of these elements in comparable detail to the current understanding of phosphorus and nitrates. That, in turn, should help to improve the Earth-systems models being developed for the next assessment of the Intergovernmental Panel on Climate Change in 2014.

Iron, for instance, is a well-studied trace element because it is involved in regulating phytoplankton production, which anchors the oceanic carbon cycle. But even so, researchers aren't sure of the iron's main sources or the key areas where it upwells from the deep sea. And lessstudied elements such as zinc and cobalt could be equally important in some cases in regulating plankton growth (M. A. Saito et al. Limnol. Oceanogr. 53, 276-290; 2008).

Another project focus is the isotopes of trace metals, which can aid studies of past climates and ocean currents. For instance, changes in neodymium-isotope levels and in the ratio between the isotopes of protactinium and thorium over time offer independent measures of the historical strength of deep-ocean currents, which are thought to selectively deplete or enhance particular isotopes in sediments.

So far, the records of these 'proxies' seem to agree in what they say about flows during some periods, such as over the past 12,000 years, but they disagree about certain events before then, during the last ice age. "The fact is, we could argue for years, but we need more data to resolve the argument," says steering committee co-chair Robert Anderson of Columbia University in New York City.

Geochemist Wallace Broecker of Columbia University, who isn't involved in GEOTRACES, calls it "a very healthy programme”. Broecker, who led a landmark mme in the 1960s and '70s focusing on the major nutrients, adds: "If they don't know what's really going on today, then of course you're going to make big mistakes in how you read the palaeo records."

Although trace metals can be essential for marine life, at high levels metals such as cadmium and copper can be lethal, and others including lead and mercury can become concentrated in ocean food chains.

And the GEOTRACES data could be used to address various environmental questions, including how ongoing changes such as the acidification of the oceans might affect trace-element cycling. "We need to understand the baseline biogeochemical cycles," says Anderson, "before we can say anything meaningful about how global change is going to affect them."

Mark Schrope 